\title{
Optimisation of the ratio of chitosan, tea polyphenols, and citric acid for avocado preservation and validation of the changes in quality
}

\section{Lina Luo}

Guizhou Provincial Academy of Agricultural Sciences

Jiaju Lu

Guizhou Provincial Academy of Agricultural Sciences

Erqi He

Guizhou Provincial Academy of Agricultural Sciences

Xiaomin Wang

Guizhou Provincial Academy of Agricultural Sciences

Shuquan Han ( $\nabla$ hanshuquan@163.com )

Guizhou Provincial Academy of Agricultural Sciences

\section{Research Article}

Keywords: Avocado, storage and preservation, tea polyphenols, chitosan, citric acid

Posted Date: August 5th, 2021

DOI: https://doi.org/10.21203/rs.3.rs-762904/v1

License: (c) (i) This work is licensed under a Creative Commons Attribution 4.0 International License. Read Full License 
1 Optimisation of the ratio of chitosan, tea polyphenols, and citric acid for 2 avocado preservation and validation of the changes in quality

3 Lina Luo, Jiaju Lu, Erqi He, Xiaomin Wang, Shuquan Han*

4 Institute of Subtropical Crops, Guizhou Provincial Academy of Agricultural Sciences, xingyi, 562400, Guizhou,china

5 , xingyi, 562400, Guizhou,china

6

$7 \quad *$ Corresponding author. Tel.: +8613158198773

8 luoluolina2021@163.com(L.-n. Luo);

9 393279705@qq.com(J.-j. Lu);

10 794961956@qq.com(E.-q. He);

11 724143637@qq.com(X.-m. Wang);

12 hanshuquan@163.com (S.-q. Han); 


\section{Abstract}

49 The effect of chitosan, tea polyphenols, and citric acid on avocado storage duration was investigated using a central 50 composite design and response surface methodology by using Design-Expert software. A quadratic polynomial regression 51 mathematical model was constructed with time as the response value to obtain the best concentration combination of 52 chitosan, tea polyphenol, and citric acid for developing the basis of a low-cost, high-efficiency storage preservative for 53 avocados. The results show that the analysis of variance of the regression model of the avocado storage duration has a $p=$ 540.0003 , indicating that the model reaches an extreme level of statistical significance, and the regression coefficient of R2= 550.9629 indicates a good fit between the model and the equation $(96.29 \%)$. The optimisation results show that the 56 preservative effect on avocados was the best when chitosan, tea polyphenols, and citric acid were combined at a 57 concentration of $1 \%, 2 \%$ and $2 \%$, respectively, and when the storage duration was 19.2 days. Validation tests confirmed 58 that this composite agent effectively delayed the decrease in hardness, the weight loss rate, the soluble solids, soluble 59 protein and vitamin $\mathrm{C}(\mathrm{VC})$ content of avocados and decreased their browning index, similar to the predicted results. These 60 results carry practical significance for guiding avocado storage and preservation technology development.

\section{Keywords}

Avocado; storage and preservation; tea polyphenols; chitosan; citric acid

CLC number:S667.9

Document code:A

\section{INTRODUCTION}

Avocado (Persea americana Mill.), also known as butter fruit and alligator fruit, is an evergreen fruit tree from family Lauraceae, genus Persea. It is native to the humid tropical and subtropical regions of Central America and Mexico (Landahl et al., 2009). Avocado pulp is sticky and delicate and has a light fragrance. It is the only fruit with a high oil content and has been nicknamed "forest butter". Avocado has high nutritional value, being rich in fat, protein, vitamins A, C, E, B1, and B2, sodium, potassium, magnesium, calcium, and other vitamins and minerals. Avocado's fat contains up to $80 \%$ unsaturated fatty acids, making it an uncommon high-energy but low-sugar fruit. It is used as food in the tropical parts of the Americas. Thus, avocado is a health fruit that has the combined qualities of fruit, grain, and oil (Meyer and Terry, 2008). Avocado has significant health-related functions, including preventing diabetes, lowering the cholesterol and blood lipid contents, protecting the liver, strengthening the stomach, clearing the intestines, and beautifying and moisturising the skin. It is regarded as a treasure among fruits in Europe, America, Japan, and other countries, being known as "forest butter" and "the source of life" (Dreher and Davenport, 2013; Ozdemir, 2004).With the consumer lifestyle changes in recent years, avocado has attracted widespread recognition as a high-energy but low-sugar fruit, and its consumption is steadily increasing. However, avocado is a respiration climacteric fruit with a short after-ripening period disenables its long-term storage and preservation, which limits the development of the avocado industry. Therefore, research on avocado preservation technologies is of particular importance.

Tea polyphenols, chitosan, and citric acid are commonly used natural preservatives that can extend the preservation period of foods. The combined use of these three preservatives can enhance the preservative effect, is relatively inexpensive, simple in operation, and non-toxic(Zheng et al., 2020).Tea polyphenols have strong free radical-scavenging capacity, which prevents lipid peroxidation. By scavenging free radicals, the activity of antioxidant enzymes is enhanced, thereby further enhancing the anti-oxidation effects (Zhang et al., 2016; Shen, 2017). The carbonyl group in citric acid can chelate the copper ions in polyphenol oxidase, inhibiting its activity to some extent, reducing the enzymatic browning and playing a role in 
89 colour preservation(Wang et al., 2021; Fan et al., 2014). Chitosan forms an extremely thin, uniform, transparent and firm film 90 on fruits, which inhibits evaporation and pathogen invasion, thereby exerting antibacterial effects(Gong et al., 2020; Guo et 91 al., 2021;Liu et al., 2021); it is widely used for preserving fruits and vegetables. Single preservatives are unable to fully meet 92 the food preservation requirements, and multiple preservatives must be combined to achieve a higher food preservation 93 performance(Zhang al., 2016; Tang and Lu, 2020; Yang al., 2020; Yang al., 2019) .Thus, composite preservatives have become 94 a popular research and development topic. In the present study, tea polyphenols, chitosan, and citric acid were selected for producing a composite with the best preservative efficacy for solving the problem of the short storage period of avocados.

\section{MATERIAL AND METHODS}

\section{Materials and reagents}

The experimental material was avocado variety Guiyan 10 collected by Guizhou Subtropical Crop Research Institute, Guizhou Academy of Agricultural Sciences, China. Plant experimental research conforms to institutional, national or international standards. We abide by the Convention on biological diversity and the Convention on trade in endangered species of Wild Fauna and flora.A total of 7.5-8 mature avocados with no pests, no damage, and uniform size were randomly selected and transported back to the laboratory on the same day.

Food-grade tea polyphenols with 99\% active ingredients were obtained from Xi'an Dafengshou Biotechnology Co., Ltd. Food-grade carboxymethyl chitosan with $99.9 \%$ active ingredients was obtained from Zhengzhou Jiajie Chemical Co., Ltd. Citric acid with 99\% active ingredients was obtained from Wuhan Wanrong Technology Development Co., Ltd.

\section{Sample treatment}

First, avocados were washed with clean water and any surface water was dried. Next, the avocados were soaked in a preservative solution for $3 \mathrm{~min}$; for the control group, no treatment was applied. The processed avocados were stored at room temperature. A total of 10 avocados were processed each time, and the experiments were performed in triplicate.

\section{Experimental design}

The central composite design method in Design-Expert software was used. An experimental design with three factors and three levels was used with the tea polyphenols, chitosan, and citric acid being independent variables and the storage duration being the dependent variable. Table 1 shows the response surface design table. Regression analysis was performed based on the established mathematical model and the optimal combination of concentrations was obtained for the composite preservative solution.

able1. The factors and levels of response surface for Avocado

\begin{tabular}{llll}
\hline \multirow{2}{*}{ Levels } & Factors & & \\
\cline { 2 - 4 } & $\mathrm{A}=$ Chitosan(\%) & $\mathrm{B}=$ Tea polyphenols(\%) & $\mathrm{C}=$ Citric acid(\%) \\
\hline-1 & 0.5 & 1.5 & 1.0 \\
0 & 1.0 & 2.0 & 2.0 \\
1 & 1.5 & 2.5 & 3.0 \\
\hline
\end{tabular}




\section{Measurement of hardness}

The fruit hardness was measured using a GY-4 digital fruit hardness tester. A thin slice of the pericarp (approximately 1 $\mathrm{mm}$ in thickness) was pared off at three equidistant locations around the equator of the avocado, and the firmness of the pulp at each location was measured using a fruit hardness tester. The hardness of each fruit was measured at three points, the measurement data was recorded and the average fruit hardness value was calculated.

\section{Determination of the weight loss rate}

The avocados were weighed. The formula used for calculating the weight loss rate is as follows:

$$
\text { Weight loss rate }(\%)=\frac{\text { weight of fruit before storage }- \text { weight of fruit after storage }}{\text { weight of fruit before storage }} \times 100
$$

\section{Browning index}

The browning index was calculated as follows:

$$
\text { Browning index }=\left[\sum \frac{\text { (grade of browning } \times \text { number of fruits })}{\text { highest grade of browning } \times \text { total number of fruits }}\right] \times 100 \%
$$

A sensory grading method was used. Grade 1 indicates no pulp browning, grade 2 indicates a slight pulp browning, grade 3 indicates a significant pulp browning not exceeding $1 / 2$ of the pulp area, grade 4 indicates a significant pulp browning exceeding $1 / 2$ of the pulp area, and grade 5 indicates the browning of all the pulp.

\section{Determination of the soluble solid content}

The soluble solid content was measured using a hand-held digital Brix refractometer. A mass of $5 \mathrm{~g}$ of avocado pulp was weighed and wrapped in six layers of gauze. A total of 2-3 drops of avocado juice were squeezed into the test port of the Brix refractometer and the value was read.

\section{Determination of the vitamin $\mathrm{C}$ content}

The VC was determined using the 2,6-dichlorophenol indophenol titration method. A mass of $2.5 \mathrm{~g}$ of avocado pulp was weighed and placed in a mortar, ground to a slurry in an ice bath, added to a $25-\mathrm{mL}$ volumetric flask and the volume was topped up with a $2 \%$ oxalic acid solution. A volume of $10 \mathrm{~mL}$ of the filtrate was withdrawn, added to an Erlenmeyer flask and titrated using a standard 2,6-dichlorophenol indophenol solution until a reddish colour that did not fade for $15 \mathrm{~s}$ appeared. The amount of dye added was recorded. In addition, $10 \mathrm{~mL}$ of a $2 \%$ oxalic acid solution were used as a blank and were titrated in the same way $(\mathrm{Yu}, 2012 ; \mathrm{Gao}, 2006)$. The experiment was performed in triplicate.

The vitamin $\mathrm{C}$ content was determined based on the dye consumption during the titration, was expressed in $\mathrm{mg}$ of ascorbic acid per $100 \mathrm{~g}$ of fresh weight $(\mathrm{FW})$ of the sample $(\mathrm{mg} / 100 \mathrm{~g} \mathrm{FW})$ and calculated as follows:

$$
\text { Ascorbic acid content }(\mathrm{mg} / 100 \mathrm{~g} \mathrm{FW})=\frac{\mathrm{V} \times\left(\mathrm{V}_{1}-\mathrm{V}_{0}\right) \times \mathrm{C}}{\mathrm{Vs}_{\mathrm{s}} \times \mathrm{W}} \times 100
$$

\section{Determination of the soluble protein content}

The Coomassie Brilliant Blue method was used to determine the protein content. In total, $0.5 \mathrm{~g}$ of avocado pulp was weighed and ground to a slurry in an ice bath. Distilled water $(5 \mathrm{~mL})$ was added and the mixture was centrifuged at $4{ }^{\circ} \mathrm{C}$ and $12,000 \times \mathrm{g}$ for $10 \mathrm{~min}$. The supernatant was collected as the soluble protein extract and stored at low temperature for 
later use. A total of $1.0 \mathrm{~mL}$ of supernatant was collected as a sample, and $5.0 \mathrm{~mL}$ of a Coomassie Brilliant Blue G-250 solution were added, mixed well and allowed to stand for $2 \mathrm{~min}$. The absorbance of the sample was measured at a wavelength of $595 \mathrm{~nm}$. A standard curve was constructed by determining the absorbance in the same way( $\mathrm{Lu}$ and $\mathrm{Li}, 2012$; Li al., 1999).The experiment was performed in triplicate.

Based on the absorbance of the solution and the corresponding amount of protein (in $\mathrm{mg}$ ) based on the standard curve, the soluble protein content in the avocado pulp was calculated as milligrams of soluble protein per gram of fruit tissue (mg/g FW), as follows:

\section{4}

165

\section{RESULTS AND DISCUSSION}

\section{Response surface methodology experiments and analysis}

The central composite design method in Design-Expert software was used to obtain comprehensive single-factor test results(Luo et al., 2021). The three independent variables were designated A (chitosan), B (tea polyphenols), and C (citric acid), and the dependent variable $\mathrm{Y}$ (storage duration) was used in an experimental design with three factors and three levels for a total of 17 design points ( 5 centre points). The mean storage duration (Y) was used as the response variable for regression analysis (Table 2). The regression equation obtained for the storage duration (Y) from the analysis is as follows:

$$
\mathrm{Y}=19.20+0.38 \mathrm{~A}+0.63 \mathrm{~B}+1.00 \mathrm{C}+0.50 \mathrm{AB}-0.25 \mathrm{AC}+0.25 \mathrm{BC}-2.60 \mathrm{~A}^{2}-2.10 \mathrm{~B}^{2}-2.35 \mathrm{C}^{2}
$$

Table 3 shows the analysis of variance of the regression model for storage duration. The regression model has a $\mathrm{p}=$ $0.0003<0.01$, indicating that the model has a very high level of statistical significance. Furthermore, the regression coefficient R2 $=0.9629>0.9$, indicating that the model and the equation have good fit (96.29\%). The lack of fit statistic was $\mathrm{F}=0.36, \mathrm{p}=0.7880>0.05$; the difference is not statistically significant, indicating a low lack of fit and a highly good fit, and that the equation is appropriate for replacing the actual design points. The influence of $\mathrm{A} 2, \mathrm{~B} 2$, and $\mathrm{C} 2$ on the value of $\mathrm{Y}$ in the equation of the selected model reached an extremely significant level, the influence of $\mathrm{B}$ and $\mathrm{C}$ on the value of $\mathrm{Y}$ in the equation reached a level of statistical significance, whereas the influence of $\mathrm{A}, \mathrm{AB}, \mathrm{BC}$, and $\mathrm{AC}$ in the equation was not statistically significant. Comprehensive comparison showed that the level of influence of each factor on the avocado storage duration in decreasing order is: citric acid $(C)>$ tea polyphenols $(B)>$ chitosan $(A) . A B$ is the interacting factor with the strongest influence on the avocado storage duration.

Table 2. Response surface design formula and experimental results

\begin{tabular}{lllll}
\hline Order number & A & B & C & Storage duration/d \\
\hline 1 & -1 & 1 & 0 & 14 \\
2 & 0 & -1 & 1 & 15 \\
3 & 0 & 0 & 0 & 20 \\
4 & 0 & 0 & 0 & 19 \\
5 & 0 & 1 & 1 & 17 \\
6 & 0 & 1 & -1 & 14 \\
7 & 0 & 0 & 0 & 20 \\
\hline
\end{tabular}




\begin{tabular}{lllll}
\hline 8 & 1 & 0 & -1 & 14 \\
9 & 1 & -1 & 0 & 14 \\
10 & 0 & 0 & 0 & 19 \\
11 & -1 & 0 & 1 & 15 \\
12 & 1 & 1 & 0 & 16 \\
13 & 0 & -1 & -1 & 13 \\
14 & 0 & -1 & 13 \\
15 & -1 & 0 & 0 & 18 \\
16 & 0 & -1 & 0 & 14 \\
17 & -1 & 0 & 1 & 15 \\
\hline
\end{tabular}

187 Table 3. Analysis of variance of the regression equation

\begin{tabular}{|c|c|c|c|c|c|c|}
\hline Source & Sum of squares & $\mathrm{df}$ & Mean squares & F-value & p-value & Significance \\
\hline Model & 92.21 & 9 & 10.25 & 20.20 & 0.0003 & $* *$ \\
\hline A & 1.13 & 1 & 1.13 & 2.22 & 0.1800 & \\
\hline B & 3.12 & 1 & 3.12 & 6.16 & 0.0421 & * \\
\hline $\mathrm{C}$ & 8.00 & 1 & 8.00 & 15.77 & 0.0054 & * \\
\hline $\mathrm{AB}$ & 1.00 & 1 & 1.00 & 1.97 & 0.2030 & \\
\hline $\mathrm{AC}$ & 0.25 & 1 & 0.25 & 0.49 & 0.5053 & \\
\hline $\mathrm{BC}$ & 0.25 & 1 & 0.25 & 0.49 & 0.5053 & \\
\hline $\mathrm{A}^{2}$ & 28.46 & 1 & 28.46 & 56.12 & 0.0001 & $* *$ \\
\hline $\mathrm{B}^{2}$ & 18.57 & 1 & 18.57 & 36.61 & 0.0005 & ** \\
\hline $\mathrm{C}^{2}$ & 23.25 & 1 & 23.25 & 45.85 & 0.0003 & $* *$ \\
\hline Residuals & 3.55 & 7 & 0.51 & & & \\
\hline Lack of fit error & 0.75 & 3 & 0.25 & 0.12 & 0.7880 & \\
\hline Pure error & 2.80 & 4 & 0.70 & & & \\
\hline Total & 95.76 & 16 & & & & \\
\hline
\end{tabular}

188 Note: **, $\mathrm{p}<0.01$, highly significant difference; $* \mathrm{p}<0.05$, significant difference.

\section{3.2. Response surface curve analysis}

191 Figure 1 shows the contour and response surface of the influence of the interaction between tea polyphenols and chitosan on 192 the avocado storage duration. When the concentration of citric acid is held constant, the response surface of the influence of 193 tea polyphenols and chitosan on the avocado storage duration exhibits a parabolic shape, first increasing and then 
decreasing. As the slope of the response surface increases, the contour line exhibits an elliptical shape. This indicates that the interaction between tea polyphenols and chitosan has a strong influence on the avocado storage duration. The contours of chitosan are dense, whereas those of tea polyphenols are sparse, indicating that chitosan has a stronger influence on the avocado's storage duration than tea polyphenols when the two factors interact.

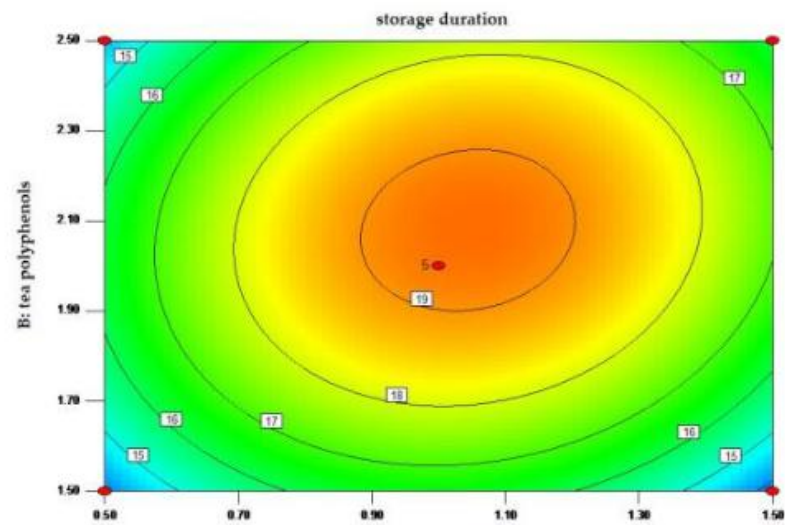

A: chitosan

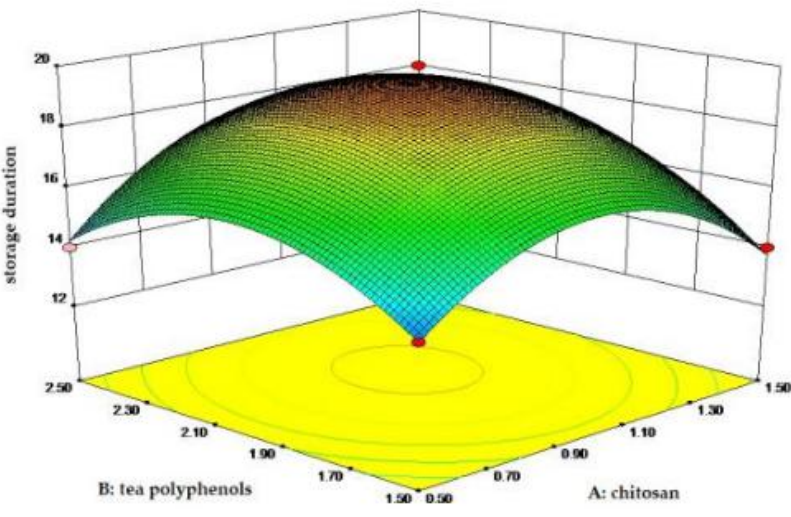

Figure1. Contour line (left) and response surface (right) of the effect of the changes in the tea polyphenol and chitosan contents on the storage duration of avocado

Figure 2 shows the contour and response surface of the influence of the interaction between citric acid and chitosan on the avocado's storage duration. When the concentration of tea polyphenols is held constant, the response surface of the influence of citric acid and chitosan on the avocado storage duration exhibits a parabolic shape. As the slope of the response surface increases, the contour line exhibits an elliptical shape. This indicates that the interaction between the two factors has a strong influence on the avocado storage duration. The contours of citric acid and chitosan are sparse, indicating that the influence of the single factors on the avocado storage duration is weak.
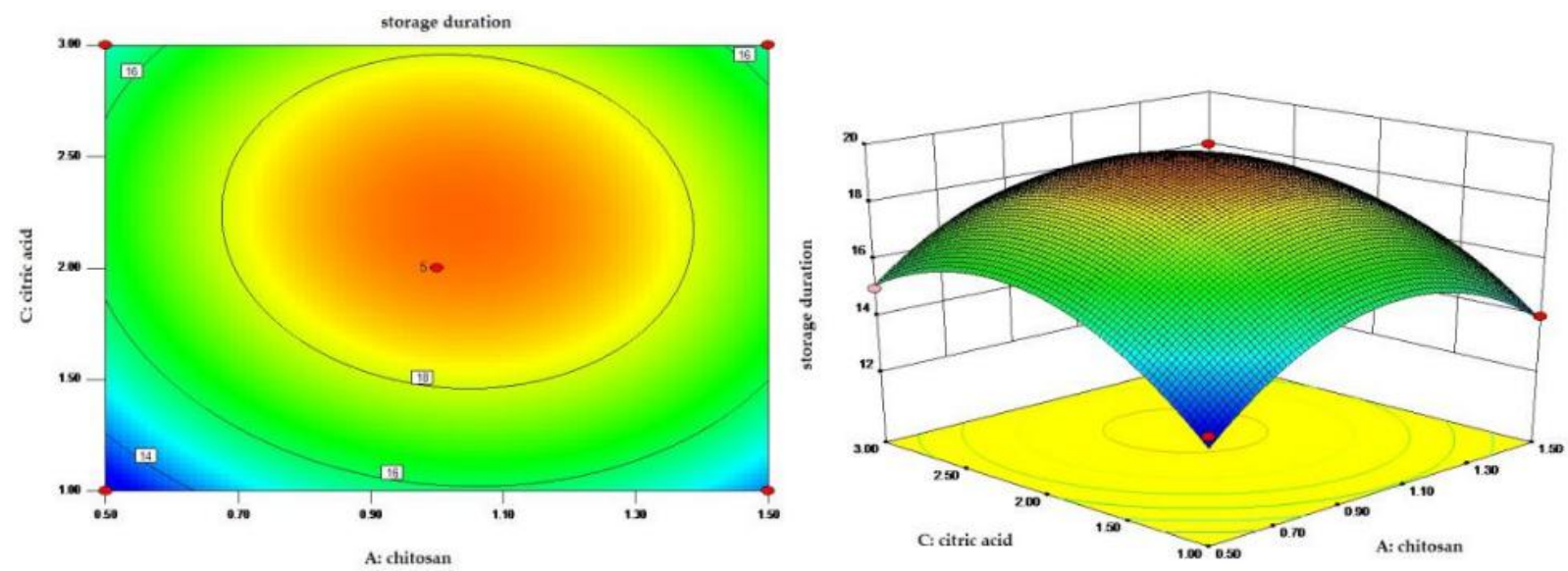

Figure 2. Contour line (left) and response surface (right) of the effect of the changes in the citric acid and chitosan contents on the storage duration of avocado

Figure 3 shows the contour and response surface of the influence of the interaction between citric acid and tea polyphenols on the avocado storage duration. When the concentration of chitosan is held constant, the response surface of the influence of citric acid and tea polyphenols on the avocado storage duration exhibits a parabolic shape. As the slope of the response surface increases, the contour line exhibits an elliptical shape. This indicates that the interaction between the 
217 two factors has a strong influence on the avocado storage duration. The contours of tea polyphenols are dense, whereas

218 those of citric acid are sparse, indicating that tea polyphenols have a stronger influence on the avocado storage duration than

219 citric acid.
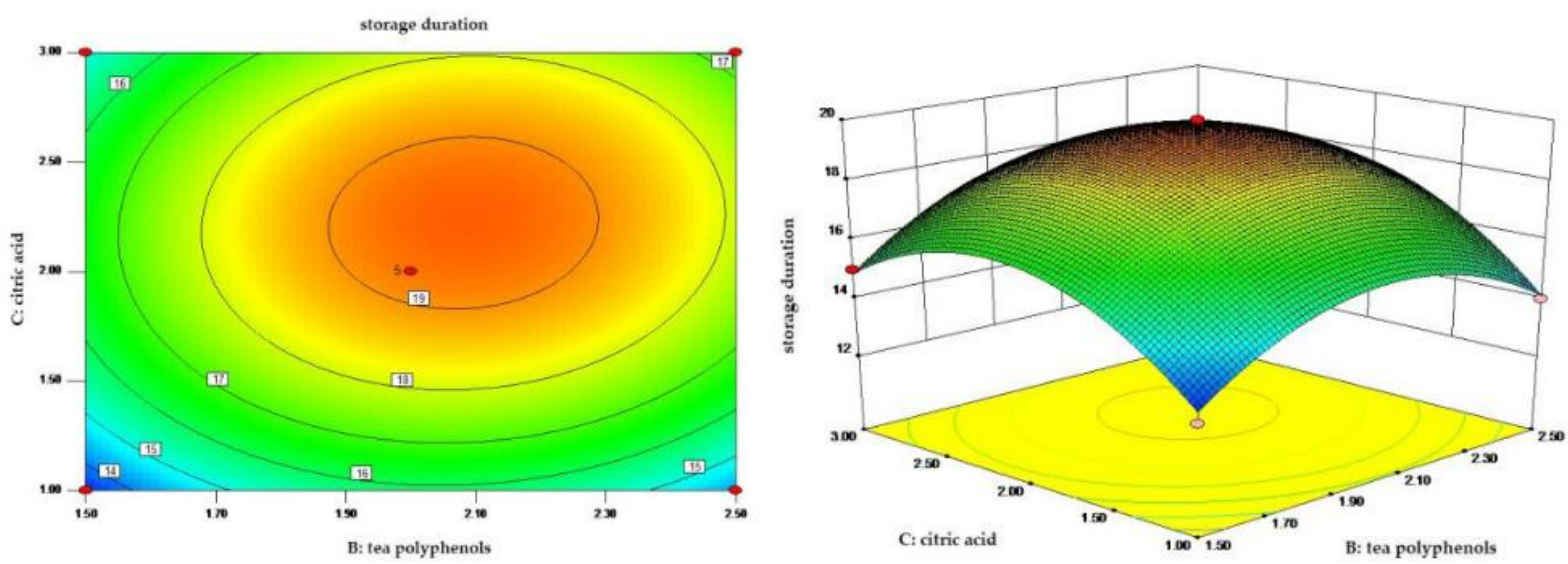

\section{4}

Figure 3. Contour line (left) and response surface (right) of the effect of the changes in the citric acid and tea polyphenol contents on the storage duration of avocado

\section{Results of tea polyphenol, chitosan and citric acid composite optimisation}

The optimisation results $\mathrm{A}=1.0, \mathrm{~B}=2.0$, and $\mathrm{C}=2.0$ were predicted using software analysis, and the value $\mathrm{Y}=19.2$ was obtained. The analysis showed that when the concentration values of tea polyphenols, chitosan, and citric acid were $1.0 \%$, $2.0 \%$, and $2.0 \%$, respectively, the storage duration of avocado was 19.2 days, and the storage and preservation effect was optimal. To validate the reliability of the prediction results, a validation test was performed to analyse the changes in avocado quality during storage.

\section{Validation test of composite optimisation}

The untreated avocados and avocados treated with $1.0 \%$ tea polyphenols, $2.0 \%$ chitosan, and $2.0 \%$ citric acid composite solution were placed at room temperature, and their quality indexes were determined after 10 days in control storage conditions and 19 days after a composite solution treatment. A comprehensive comparison was performed to validate the changes in avocado quality during storage after treatment with the composite preservative.

\section{weight loss}

Figure 4A shows the changes in the weight loss rate of the avocados. The weight loss rate gradually increased with the increasing storage duration. The water loss of the avocados in the control group increased and decreased rapidly in the first 10 days. The treatment with the composition preservative solution delayed water loss to some extent and inhibited the increase in the water loss rate. Up to day 19 , the weight loss rate in the treatment group was significantly lower than that in the control group. 

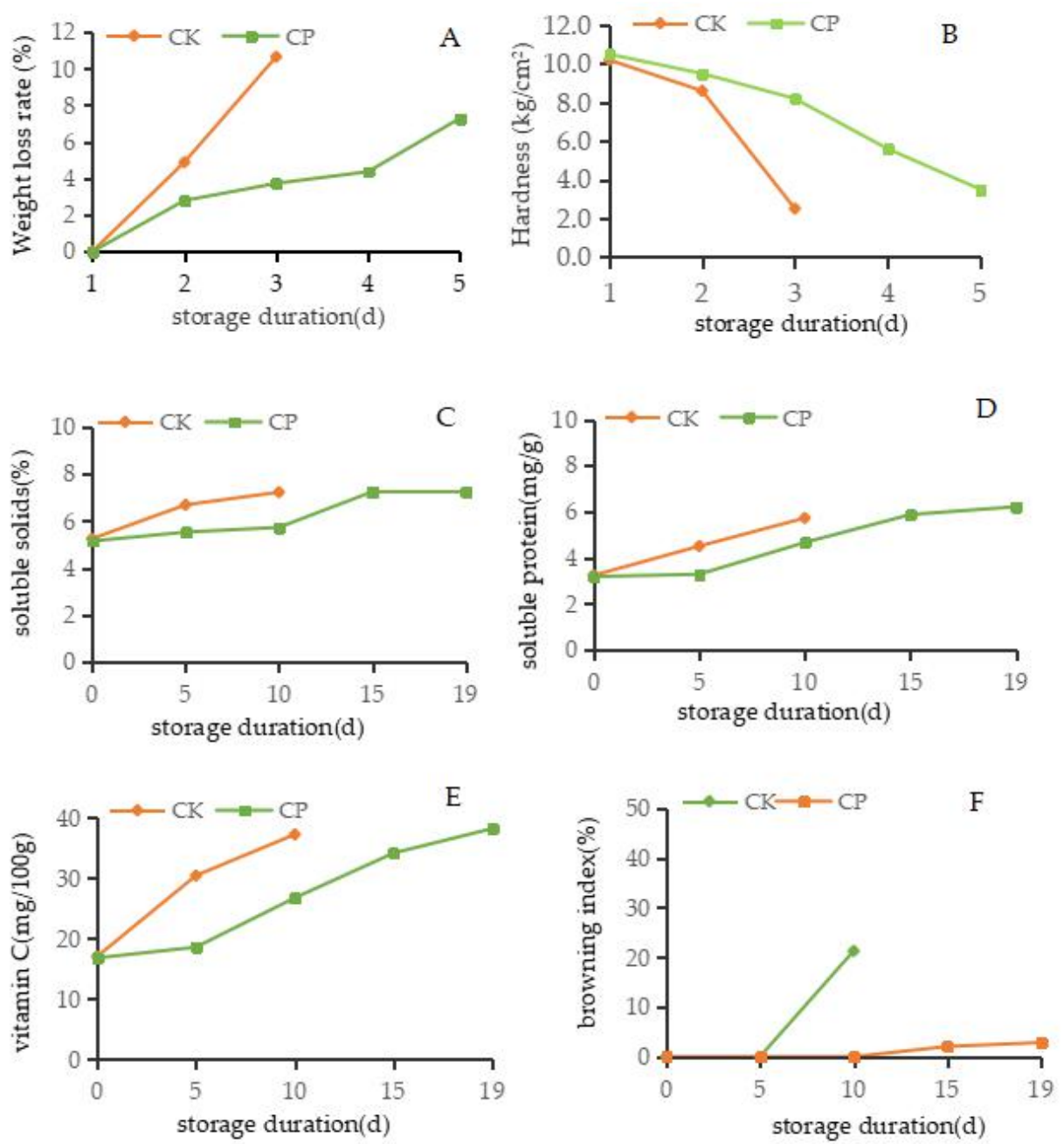

Figure 4. Effect of the composite solution on the avocado weight loss rate(A), hardness(B), soluble solids(C),soluble protein(D), vitamin $\mathrm{C}(\mathrm{E})$ and browning index(F);PLA: poly(lactic acid).

CK: avocados untreated; CP: avocados treated with $1.0 \%$ tea polyphenols, $2.0 \%$ chitosan, and $2.0 \%$ citric acid composite solution.

\section{Hardness}

The hardness of the avocados decreased with an increasing storage duration (Figure 4B). The hardness of the avocados was initially measured at $10 \mathrm{~kg} / \mathrm{cm} 2$, but the treatment with the composite preservative solution significantly inhibited the decrease in hardness. At 10 days of storage, the hardness of the control group avocados was $2.5 \mathrm{~kg} / \mathrm{cm} 2$. At 19 days of storage, whereas the hardness of the treatment group avocados was $3.5 \mathrm{~kg} / \mathrm{cm} 2$, the hardness remained at a high level.

\section{Soluble Solids}

Figure $4 \mathrm{C}$ shows that the soluble solid content of the avocados in the control group increased continuously. At 10 days of storage, the maximum content of soluble solids was $7.22 \%$. After treatment with the composite preservative solution, the soluble solid content increased slowly over the first 10 days, rapidly increased to a peak at $7.24 \%$ on day 15 , and then remained unchanged between days 15 and 19 .

\section{Soluble Protein}

Figure 4D shows that the soluble protein content of the control group increased rapidly during storage, reaching $5.72 \mathrm{mg} / \mathrm{g}$ on day 10. The treatment with the composite preservative solution delayed the change in the soluble protein content. At day 15 of storage, the soluble protein content in the treatment group was similar to the maximum content observed in the control 
group. On day 19, the soluble protein content increased to $6.21 \mathrm{mg} / \mathrm{g}$, indicating that the composite preservative solution

A

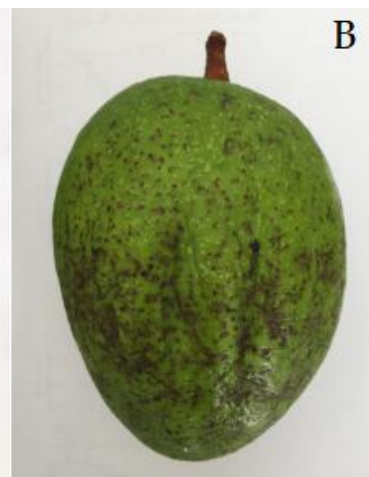

B

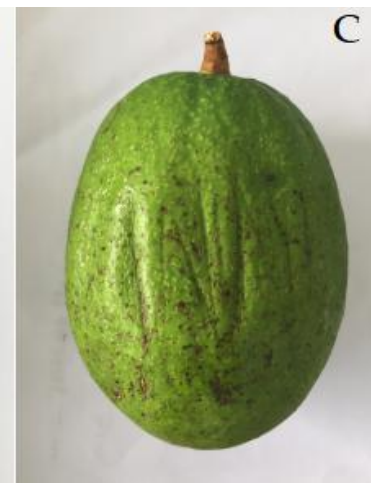

C

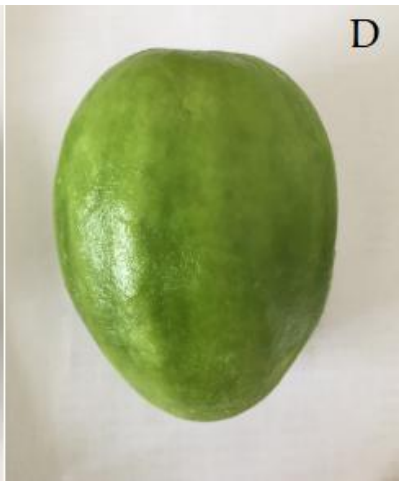

Figure 5. Changes in the avocado skin Day 1 of storage (A), day 10 in the control group (B), day 19 in the treatment group (C) and pulp on day 19 in the treatment group (D).

\section{DISCUSSION}

Avocado is a respiration climacteric fruit with strong post-harvest metabolism, a short after-ripening period, and a short preservation period. It matures and softens within 5-7 days at room temperature, and is susceptible to microbial infections that cause anthracnose, brown rot, stalk rot, and other diseases. The skin colour of avocados rapidly changes to brown, the pulp decays, the quality and flavour deteriorate rapidly and they lose commercial value, which cause severe economic losses(Wang et al., 2010; Cao et al., 2013). Currently, the avocado preservation technologies used in China are not advanced, which severely limits the development of the avocado industry(Bao, 2017).Avocado preservation methods are broadly divided into two categories: chemical and physical preservation. Chemical preservation primarily uses fungicides to prevent fruit rot and delay ripening. Physical methods primarily include heat treatment, low temperature storage, low-pressure storage, and modified atmosphere packaging. The disadvantages of physical preservation include the high cost and poor 
efficacy; for chemical preservation, the selection of a suitable preservative is essential. Currently, many studies on produce storage and preservation techniques have been conducted, but relatively few have focused on avocado. Wei et al. studied the inhibitory effects of various fungicides on ulcers and anthracnose in avocado, and the results showed that $45 \%$ prochloraz and 10\% difenoconazole are effective in inhibiting anthracnose and ulcers, respectively(Wei, 2015; Wei, 2014). A study by Huang et al. found that SporGon at a low concentration could delay the post-harvest decay of Guiken III and Hass avocados(Huang et al., 2010). Treating avocado fruit with a wax containing $0.4 \%$ thiabendazole and $0.1 \%$ benomyl reduced the incidence of post-harvest diseases and extended the shelf life by 2-3 days(Sisler et al., 1996) .A study by Zhong et al. on avocado fresh-keeping duration after a 1-MCP treatment and a chitosan coating showed that 1-MCP delayed ripening(Zhong and Xia, 2006). A study by Luo et al. on the effects of different concentrations of tea polyphenols on the post-harvest avocado storage and preservation showed that the treatment with $2.0 \%$ tea polyphenols controlled the changes in avocado quality and physiology, thereby prolonging its storage duration. Bao et al. treated avocados with different concentrations of bergamottin and found that a concentration of $5 \mathrm{~mL} / \mathrm{L}$ showed the best preservative effect of inhibiting the storage damage and prolonging the shelf life(Bao et al., 2017). To date, no studies on the effect of tea polyphenols, chitosan, and citric acid on the avocado storage and preservation have been conducted. Thus, in this study, the concentrations of these preservatives were optimised using response surface methodology to obtain the optimal combination of concentrations for the most effective storage and preservation. In addition, validation experiments were conducted to provide a better basis for improving avocado storage and preservation.

Response surface methodology establishes a continuous variable surface model by optimising the experimental conditions, evaluating the influencing factors and their interactions, analysing the optimal level range of each factor, optimising and evaluating their interacting effects, and determining the statistical method with the optimal conditions in the multi-factor system, to produce a more intuitive and accurate result(Xie et al., 2021; Zheng et al., 2021). In the present study, a regression model with the avocado storage duration as the response value was established using a response surface methodology. The model achieved a very high level of statistical significance, with a good fit (96.29\%) between the model and the equation. The optimisation results indicated that the avocado storage duration was 19.2 days when chitosan, tea polyphenols and citric acid were combined at concentration values of $1 \%, 2 \%$, and $2 \%$, respectively. The comprehensive comparison results showed that the level of influence of each factor on the avocado storage duration in decreasing order is: citric acid $>$ tea polyphenols $>$ chitosan. The composite solution of $1 \%$ chitosan, $2 \%$ tea polyphenols and $2 \%$ citric acid effectively prolonged the avocado storage duration. The validation test results showed that a composite solution of $1.0 \%$ tea polyphenols, $2.0 \%$ chitosan, and $2.0 \%$ citric acid significantly extended the storage duration of the avocados and controlled the deterioration of their quality. Compared with the control group at 10 days of storage, the treatment group at 19 days of storage, which was treated using the composite solution, showed a slower decrease in the weight loss rate, and the hardness and the soluble solid, soluble protein, and VC contents did not decrease, indicating that the original quality was maintained. Moreover, the browning index was lower than $5.0 \%$, thus the reliability of response surface optimization results is verified.

\section{CONCLUSION}

The central composite design method of design expert software was used, with a (tea polyphenols), B (chitosan), C (citric acid) as independent variables and Y (storage time) as dependent variables. The results showed that the order of the factors affecting the storage period of avocado was citric acid $>$ tea polyphenols $>$ chitosan. It was predicted that the best 
concentration combination for the preservation of avocado was the mixture of $1 \%$ chitosan, $2 \%$ tea polyphenols and $2 \%$ citric acid, and the storage time of avocado was 19.2 days.

In order to verify the reliability of the prediction results, the quality changes of avocado during storage were tested. The hardness, soluble solids, soluble protein and Vc content of avocado were still higher after 19 days treatment with $1.0 \%$ tea polyphenols, $2.0 \%$ Chitosan and $2.0 \%$ citric acid. The weight loss rate decreased slightly and the browning index increased slowly. These results were similar to the predicted ones, further confirming the reliability of the response surface methodology optimisation results. Thus, the composite solution of $1 \%$ chitosan, $2 \%$ tea polyphenols, and $2 \%$ citric acid effectively prolonged the post-harvest storage duration of avocados.

\section{DECLARATION OF CONFLICTING INTERESTS}

The authors declare no conflict of interest.

\section{FUNDING}

This study was supported by Science and Technique Foundation of Guizhou Province (No. [2019]2268).

\section{REFERENCES}

Landahl S, Meyer M D, Terry L A. Spatial and temporal analysis of textural and biochemical changes of imported avocado cv. Hass during fruit ripening[J]. Journal of Agriculture and FoodChemistry,2009,57:7039-7047.[http://dx.doi.org/10.1021/jf803669x]

Meyer M D, Terry L A. Development of a rapid method for the sequential extraction and Subsequent quantification of fatty acids and sugars from avocado mesocarp tissue[J]. Journal of Agriculture and FoodChemistry,2008,56:7439-7445.[http://dx.doi.org/10.1021/jf8011322]

DREHER M L, DAVENPORT A J. Hass avocado composition and potential health effects[J]. Critical Reviews in Food Science and Nutrition, 2013, 53(7): 738-750.[http://dx.doi.org/10.1080/10408398.2011.556759]

Ozdemir F, TopuzA. Changes in dry matter, oil content and fatty acids composition of avocado during harvesting time and post-harvesting ripening period[J]. Food Chemistry,2004,86:79-83.[http://dx.doi.org/10.1016/j.foodchem.2003.08.012]

Zheng,L.P.; Wang,H.;,Li,Y.L.Development and application of fresh cut yam preservative [J]. Journal of Zhongzhou University, 2020,37 (04): 120-124.[10.13783/j.cnki.cn41-1275/g4.2020.04.024]

Zhang,Y.H.; Wang,R.R.;,Xing,S.J.Research progress on Application of tea polyphenols in fruit and vegetable storage [J]. Food research and development, 2016, 37 (11): 210-214.[10.3969/j.issn.1005-6521.2016.11.050]

Shen, R.Y.;Research progress on the application of tea polyphenols in food storage [J]. Food engineering, 2017 (04): 12-13 + 57.[10.ssss/j.issn.1673-6044.2017.4.003]

Wang,W.T.; Ding,X.Y.;Jiang, S.;Ma,K.; Lin,R., Ren, Q.P.Effects of different concentrations of citric acid on preservation of Gladiolus [J]. Forestry science and technology communication, 2021 (02): 73-77.[10.3969/j.issn.0517-6611.2007.36.053]

Fan,L.L.; Zhao,W.J.;, Zhao,D.;Zhao,H.X.;Li,M.M.; Cai,X.T.;Feng,X.Q.Preservation effect of citric acid treatment on fresh cut apple [J]. Food science, 2014,35 (18): 230-235.[10.13995/j.cnki.11-1802/ts.201501048]

Gong,Y.X.Y.; Zhou,Y.Y.;Wen,J.Y.;Ding,L.S.;Xie,Jing. Research progress on the application of tea polyphenols and chitosan in food preservation [J]. Preservation and processing, 2020,20 (03): 217-221 + 225.[CNKI:SUN:BXJG.0.2020-03-038] 
Guo,J.H.;Zhang,Z.S.;Ma,X.;Cheng,S.N.Effect of compound film of Zanthoxylum bungeanum extract and chitosan on preservation of Dongzao [J]. Food engineering, 2021 (01): 20-24.[]

Liu,C.X.,Qiao,Y.J.;Kang,H.F.;Chen,B.J.;Zhang,Y.;Lei,T.H.Effect of low temperature combined with chitosan coating on storage quality of 'Xiahei' grape [J]. Acta AGRICULTURAE Sinica Sinica, 2021,37 109-115.[10.15955/j.issn1000-3924.2021.02.20]

Zhang,Z.;Liu,Q.;Zhang,Q.;Niu,H.;Gao,m.k.;Chen,P.Effects of compound preservatives on Postharvest Physiology and quality of wax apple [J]. Food industry science and technology, 2016,37 (17): 322-325.[10.13386/j.issn1002-0306.2016.17.054]

Tang,Y.j.;Lu,X.X.Research progress of edible film composite biological preservative in fruit and vegetable preservation [J]. Food research and development, 2020,41 (18): 213-218.[CNKI:SUN:SPYK.0.2020-18-038]

Yang,Y.L.;Yuan,Q.L.;Wang,D.;Cai,M.Y.;Gao,Z.S.;Zhang,Q.S.;Guo,S.J.Effect of compound coating preservative on quality of Annona squamosa during simulated storage and transportation [J]. Journal of northwest agriculture, 2020,29 (07): 1106-1115.

Yang,Y.J.;Han,Y.Z.;Meng,X.;Wang,Y.Y.;Li,K.;Xu,S.Q.;Myrica,R.Preservation effect of cinnamaldehyde antibacterial composite preservative film on Postharvest litchi [J]. Food science, 2019,40 (23): 253-261.[CNKI:SUN:SPKX.0.2019-23-037]

Yu,G.P.Food Biochemistry Experiment [M]. Beijing: China Forestry Press, 2012: 93-95.

Gao,J.F.Experimental guidance of plant physiology [M]. Beijing: Higher Education Press, 2006:142.

Lu,W.J.;Li,Y.S.Experimental course of plant physiology [M]. Beijing: China Forestry Press, 2012: 106-107.

Li,H.S.;Sun,Q.;Zhao,S.J.Experimental principles and techniques of plant physiology and biochemistry [M]. Beijing: Higher Education Press, 1999:167-168.

Luo,L.N.;Han,S.Q.;Fan,Ji.X.;Ma,W.H.;Wang,D.G.;Zhang,Z.X.;He,F.P.Evaluation of the effect of tea polyphenols on the preservation of avocado fruit [J]. Food industry science and technology, 2021,42 (02): 284-289.[10.13386/j.issn1002-0306.2020030123]

Wang,Y.;Huang,L.J.;Huang,X.M.;Zhang,Z.Q.;Chen,Z.X.Research progress on storage and preservation technology of avocado [J]. Guangdong Agricultural Sciences, 2010 (8): 167-169.[10.16768/j.issn.1004-874x.2010.08.079]

Cao,H.Y.;Chen,Y.L.;Li,W.F.Study on storage suitability of avocado fruit [J]. Agricultural research and application, 2013 (41): 20-23.[10.3969/j.issn.2095-0764.2013.04.005]

Bao,D.H. Comparative study on the Storability of avocado and the effects of 1-MCP and tangerine on the preservation of avocado [D]. Hainan University, 2017.

Wei,W.T.Antibacterial effect of different fungicides on the pathogen of avocado canker [J]. Jilin Agricultural Sciences, 2015 (2): 68-70, 91.[10.16423/j.cnki.1003-8701.2015.02.019]

Wei,W.T.Antibacterial effect of different fungicides on Colletotrichum gloeosporioides [J]. Guizhou Agricultural Sciences, 2014 (5): 125-127.[10.3969/j.issn.1001-3601.2014.05.032]

Huang,L.J.;Wang,Y.;Chen,Z.X.;Zhang,Z.Q.;Huang,X.M.Study on storage and fresh-keeping technology of Hasi avocado [J]. South China fruit tree, 2010 (1): 41-44.[CNKI:SUN:FRUI.0.2010-01-020]

Sisler E C, Dupille E, Serek M. Inhibitors of ethylene responses in plantsat thereceptor level:recent developments [J].Physiol Plant, 1996,100:577-582.[10.1034/j.1399-3054.1997.1000320.x]

Zhong,Q.P.;Xia,W.Study on delaying ripening of avocado fruit by 1-mpc combined with glycan coating [J]. Chinese Journal of food, 2006 (3): 95-99.[10.16429/j.1009-7848.2006.03.018]

Bao,D.H.;Li,S.P.;Wu,F.;Li,C.L.;Gao,X.;Fu,Y.N.;Li,R.;Li,M.F.Effect of tangerine on the preservation of Hasi avocado [J]. Food science and technology, 2017,42 (04): 251-255 + 261.[CNKI:SUN:SSPJ.0.2017-04-056] 
409 Xie,X.Y.;Fan,Y.;Wang,W.;Jing,B.N.;Chen,T.X.;Liu,Y.Q.;Yan,H.P.;Cao,L.F.Optimization of fermentation technology of $410 \quad$ Polysaccharides from Pyrus spinosa fruit by response surface methodology [J]. Brewed in China, 2021,40 (04): 177-182.

411 Zheng,Z.;Pang,L.J.Optimization of ultrasonic assisted extraction of pectin from agaric by box Behnken response surface method 412 and analysis of its antioxidant activity [J]. Food science and technology, 2021,46 (04): 413 173-179.[10.13684/j.cnki.spkj.2021.04.027] 


\section{Supplementary Files}

This is a list of supplementary files associated with this preprint. Click to download.

- Highlights.pdf 